Shelley L. Birdsong

\title{
The Last King(s) of Judah
}

Zedekiah and Sedekias in the Hebrew and Old Greek Versions of Jeremiah 37(44):140(47):6

[Die letzten Könige von Juda. Zedekia und Sedekias in der hebräischen und altgriechischen Fassung von Jeremia 37(44):140(47):6.]

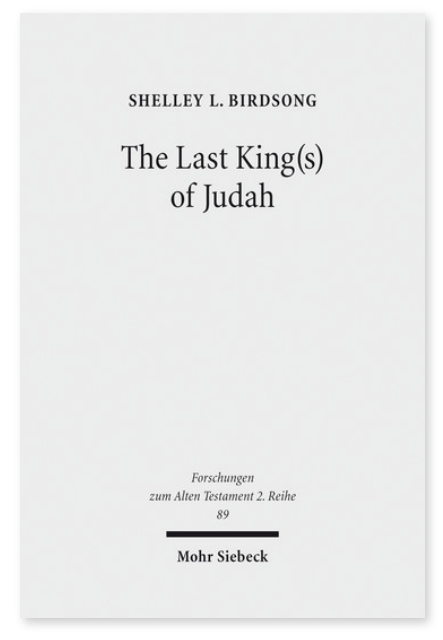

2017. XVII, 255 Seiten. FAT II 89

ISBN 978-3-16-153889-6

DOI 10.1628/978-3-16-153889-6

eBook PDF $99,00 €$

ISBN 978-3-16-153888-9

fadengeheftete Broschur 99,00€
Veröffentlicht auf Englisch.

Zedekia ben Josia war der letzte König von Juda und unter seiner Herrschaft wurde im Jahre 586 v.Chr. Jerusalem zerstört. Interessanterweise zeichnen die hebräische und die griechische Fassung von Jeremia sehr unterschiedliche Bilder von Zedekia und werfen dadurch eine Reihe literaturwissenschaftlicher und historisch-kritischer Fragen auf. Shelley L. Birdsong beleuchtet in dieser Untersuchung kritisch die beiden Charakterisierungen von Zedekia und befasst sich text- und formkritisch mit deren Beziehung. Sie zeigt, dass der griechische Text Zedekia als manipulativen und mysteriösen machiavellischen Fürsten darstellt, wohingegen die hebräische Übersetzung ihn als zögerlichen und gütigen König beschreibt, der metaphorisch den Sturz seines Königreichs widerspiegelt. Im Anschluss an diesen literarischen Vergleich, wendet die Autorin verschiedene wissenschaftliche Methoden an, um zu belegen, dass der hebräische Text später bearbeitet wurde.

Shelley L. Birdsong Born 1982; 2004 BA in Biblical Studies; 2008 MA in Hebrew Bible and Philosophy of Religion; 2014 PhD in Hebrew Bible; 2014-15 Visiting Assistant Professor of Biblical Studies at Azusa Pacific University (CA); 2015-17 Visiting Assistant Professor of Religion at North Central College (IL).

Jetzt bestellen:

https://mohrsiebeck.com/buch/the-last-kings-of-judah-9783161538896?no_cache=1

order@mohrsiebeck.com

Telefon: +49 (0)7071-923-17

Telefax: +49(0)7071-51104 